\title{
Observations and suggestions during COVID-19: Harnessing pre-existing elements to increase food security
}

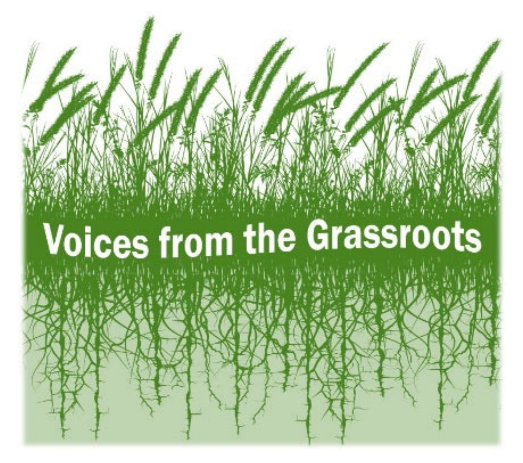

\author{
Neil Cox ${ }^{a *}$ and Zoe Beynon-MacKinnon ${ }^{b}$ \\ Lettuce Harvest Foundation
}

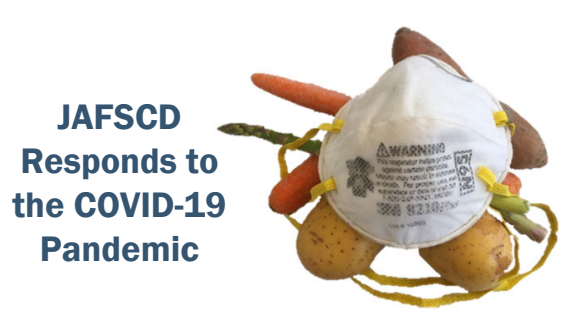

Submitted September 30, 2020 / Published online December 9, 2020

Citation: Cox, N., \& Beynon-MacKinnon, Z. (2020). Observations and suggestions during COVID-19:

Harnessing pre-existing elements to increase food security. Journal of Agriculture, Food Systems, and

Community Development, 10(1), 25-27. https://doi.org/10.5304/jafscd.2020.101.035

Copyright (C 2020 by the Authors. Published by the Lyson Center for Civic Agriculture and Food Systems. Open access under CC-BY license.

\begin{abstract}
Founded in 2019, Lettuce Harvest Foundation (LHF) is a grassroots urban agriculture nonprofit organization based in Vancouver, Canada. As an organization just launching as COVID-19 took hold, LHF's programming has been designed to enable urban agriculture in light of the pandemic's challenges. This article presents observations and suggestions gained from LHF operations as an organization with limited resources. When COVID-19 put stress on the global food system, it revealed that short-term emergency food relief is

a * Correspondence author: Neil Cox, Director of Strategy, Lettuce Harvest Foundation, Vancouver, British Columbia, Canada; +1-604-329-7768; neilcoxwv@gmail.com

b Zoe Beynon-MacKinnon, Director of Operations, Lettuce Harvest Foundation, Vancouver, British Columbia, Canada; +1-778-866-4084; info@,lettuceharvesttogether.com
\end{abstract}

insufficient, indicating an urgent need for redesigning our food system. Harnessing pre-existing industry elements for accessible resources is one proposed method that grassroots organizations can adopt to mitigate strains on our food system inflicted by COVID-19 and other future crises.

\section{Keywords}

Climate Emergency, COVID-19, Food Security, Global Food Governance, Urban Farming, Grassroots Organizations

\section{Acknowledgments}

Thank you to all Lettuce Harvest Foundation staff and members for their enduring enthusiasm and support and to the generous Vancouver community. Lettuce Harvest Foundation works and learns on the unceded territory of the Coast Salish peoples-Sknwxwwú7mesh (Squamish), Stó:lō and

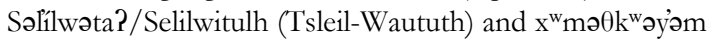
(Musqueam) Nations. 


\section{Introduction}

Lettuce Harvest Foundation (LHF) is a Vancouver-based urban agriculture nonprofit organization founded in 2019. We transform underutilized yards into volunteer-run urban agriculture sites called Community Farmyards, distributing the harvest throughout our community. We see urban food production as a way to benefit volunteers' diets and build community connections while engaging in climate action and enhancing food security at large. Our role is connecting homeowners with underutilized space to community volunteers and providing expertise to produce a harvest and support a resilient food system.

Though founded in 2019, LHF's urban farms have operated solely in 2020. As such, COVID-19 has defined our initiative development. Our programming is designed to allow for physical distancing, limited group size, and altered food and financial security. This article places LHF in the context of COVID-19, shares what we have learned, and explores two observations with suggestions to grassroots organizations operating during COVID-19.

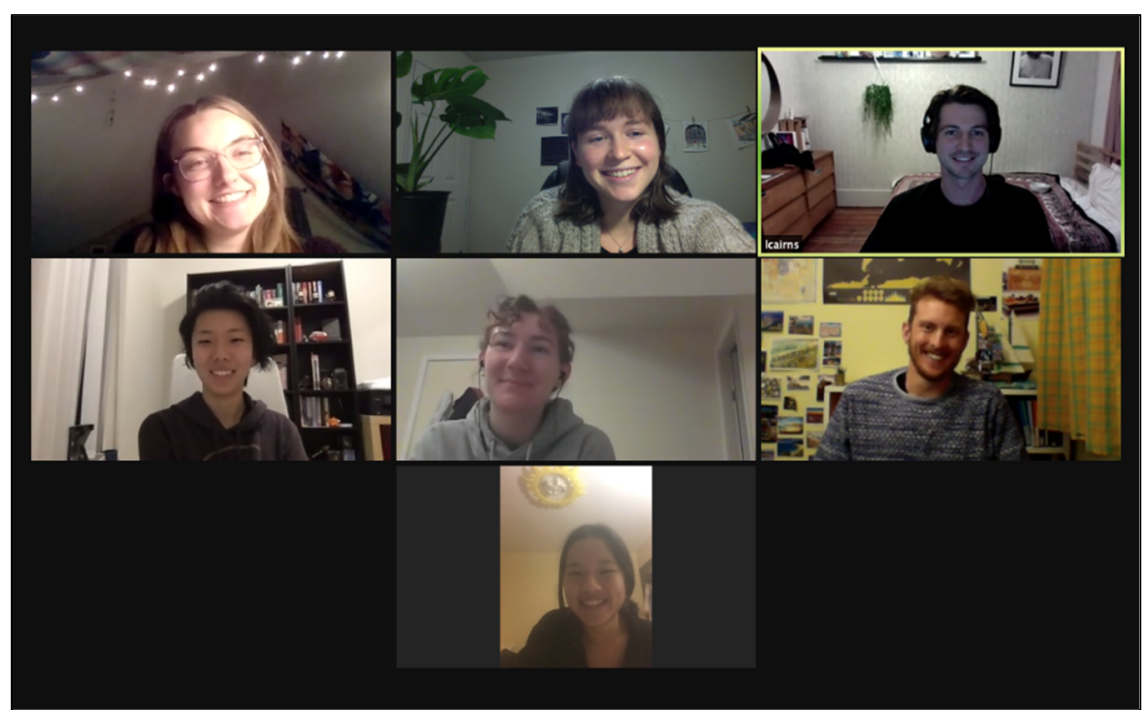

The Lettuce Harvest Foundation team in a weekly updates meeting. Photo credit: Zoe Beynon-MacKinnon

\section{Observations}

We have observed two significant aspects affecting operations. Firstly, COVID-19 has exposed vulnerabilities in our food system, emphasizing the urgent need to focus on a long-term solution rather than react as is typical with short-term responses such as emergency food relief. Vulnerabilities exposed by COVID-19 have regularly manifested in people doubting the safety of grocery store food and increasing their interest in selfprovisioning gardens. Secondly, COVID-19 has restricted organizations' resources and complicated the development of safe initiatives. We suggest a mindset change to mitigate this by harnessing pre-existing industry elements as resources, potentially benefiting long-term food security.

\section{Observation One}

COVID-19 has shed light on the many holes within our food system that have been long overlooked and underrated. It has placed the necessary strain on the system to exemplify just how vulnerable the global supply chain is to large-scale disruption. While this requires immediate and substantial

emergency food relief, to do so without also assessing and reorganizing our food system is ill-guided. Due to the growing presence of the climate breakdown in daily life, we know that 2020 is just the beginning of a series of largescale disasters and disruptions to the global supply chain. LHF, like many other grassroots nonprofit organizations, is therefore working to change this network, building back a more resilient and responsive food system.

While the need for broad systems change seems self- 
explanatory to us, the majority of funding and investment into COVID-19 food relief is focused solely on operations that maintain and support the status quo of food production, distribution, and consumption. We therefore advocate for a paradigm shift around the harnessing of underutilized spaces and resources. In the case of LHF, this takes the form of working with front and back yards donated by homeowners that can be collectively gardened by community members.

\section{Observation Two}

Recognizing challenges of implementing long-term solutions to food system strains, we suggest a shift in organizational mindset. We have learned that although COVID-19 inhibits operations and resource acquisition, particularly for grassroots organizations, harnessing pre-existing industry elements as resources is effective. 'Pre-existing elements' refers to unique industry factors that are underutilized and potentially available for use. With COVID-19 threatening survivability, organizations are forced to think creatively about what is valuable. By maintaining this forced mindset after COVID-19 restrictions ease, long-term food system vulnerabilities may be mitigated. On an organizational level, this could increase adaptability and productivity. On a large scale, it could increase resilience during crises, cumulatively enhancing food security using limited resources.

One significant LHF challenge has been obtaining volunteers and yards during COVID-19. LHF utilizes agricultural knowledge and preexisting land, which are integral, underutilized agricultural inputs. Our summer 2020 plans assumed that growing food was unreasonable, given COVID-19 restrictions. However, with the unexpected support of homeowners, we obtained previously unavailable land and are now growing food in yards that exist whether or not they are used to produce food. In this way, the land is used twice: once as a private yard, and again as a Community Farmyard.

We suggest considering how pre-existing elements extraneous to regular operations, such as community members' yards, could fulfill organizational needs (in our case, these include volunteer knowledge, community garden waitlists, rejected produce, etc.). What is seemingly useless? What is available to your organization and underutilized by others? Can we use COVID-19 factors to enhance food security, such as by utilizing closed parking lots or constructing portable farms? Conventional development requires time and money inaccessible to grassroots organizations during crises. Changing the mindsets of those influencing food security can increase food resilience, enhancing our collective ability to respond and prepare for crises by normalizing quick responses using pre-existing elements. Our hope is that the vital, crisis-driven, creative solutions to food system strains endure, mitigating future challenges and large-scale disruptions.

\section{Conclusion}

COVID-19 has exposed vulnerabilities in our global food system that are exacerbated by the looming threat of climate change and disasters requiring short-term relief. LHF, with other grassroots organizations, is working toward systemic change in perceptions of our food system. A change in mindset, though arduous, may eventually create solutions to organizational challenges. Organizations are essential in reorganizing responses to crises from short-term relief to long-term solutions. One potential solution is harnessing preexisting elements as resources to increase organizational adaptability and collective food security. Addressing food insecurity requires us to be conscious of vulnerabilities and to reimagine the structure of our food system using the resources at hand. 